\title{
Vision screening in children tested at 7, 11, and 16 years
}

\author{
A D TIBBENHAM, C S PECKHAM, P A GARDINER
}

British Medical fournal, 1978, 1, 1312-1314

\section{Summary and conclusions}

Distant vision screenings of a national sample of children were performed at the ages of 7,11 , and 16. Many children with normal vision at one screening showed defects at later screenings, and altogether $18 \%$ of children with normal vision at the age of 7 had defects by the time they were 16. Twelve per cent of those with normal vision at 7 and 11 had developed a visual defect by the age of 16 . Apparent improvements between screenings probably resulted largely from technical difficulties inherent in testing young children.

The results clearly indicate the importance of regular vision screening during the school years and the need for comprehensive but flexible back-up services.

\section{Introduction}

To plan ophthalmological services for children it is necessary to know the proportion of children with visual defects and to assess changes in visual acuity during childhood. In 1973 Ingram recorded that three-quarters of children aged 5 to 15 who were referred to school eye clinics after routine sight tests had some ocular defect. He concluded that it was important to perform routine sight tests throughout a child's school career. ${ }^{1}$ Ingram's article prompted discussion on the possible role of a children's eye clinic, ${ }^{2-1}$ and more recently the value of vision screening of children has been debated..$^{5-10}$ We report here data on the distant vision screening of a nationally representative sample of schoolchildren at the ages of 7,11 , and 16 years.

\section{Method}

The National Child Development Study, carried out by the National Children's Bureau, is a longitudinal survey of all children

National Children's Bureau, London EC1V 7QE

A D TIBBENHAM, BA, research officer

Charing Cross Hospital, London

C S PECKHAM, MD, MFCM, senior lecturer in community medicine

Guy's Hospital, London

P A GARDINER, MD, DOMs, research fellow in ophthalmology born in England, Wales, and Scotland from 3 March to 9 March 1958. ${ }^{11}$ Medical, social, and educational data on these children were collected when they were aged $7,,^{12} 11,1^{13}$ and $16 .^{14}$ The medicale examination included tests for screening distant and near vision. Near $\overline{0}$ vision tests, performed at 11 and 16 only, are not referred to here.? The results of vision screening at 7 and 11 years ${ }^{15} 16$ have already been $\varnothing$ reported, but we have examined the longitudinal aspects of distant vision screening in relation to the degree of change in acuity between $\vec{\theta}$ the three tests.

Screening procedure-A standard Snellen chart composed of block capital letters without serifs was used. Testing was carried out at a. distance of 6 metres and instructions were given to place the chart in a good light, level with the child's eye, and free from glare. Each eye 3 . was tested separately, with the other eye occluded without pressure-on the eyeball.

Vision grouping-The children were categorised according to their $\vec{N}$ visual acuity, when tested without glasses, into the following groups: $\omega$ normal vision $-6 / 6$ or better in both eyes; minor defect $-6 / 6,6 / 9$ or $\vec{\omega}$ $6 / 9,6 / 9$; unilateral moderate defect $-6 / 6$ or $6 / 9$ in better eye, $6 / 12$ or $\vec{N}$ $6 / 18$ in other eye; unilateral severe defect- $6 / 6$ or $6 / 9$ in better eye, $ᄋ$ $6 / 24$ or worse in other eye; bilateral moderate defect $-6 / 12$ or $6 / 18$ in better eye; bilateral severe defect-6/24 or worse in better eye. Allo children with moderate or severe impairment of visual acuity, whether 3 unilateral or bilateral, were considered to have definite defects.

\section{Results}

Only the 8339 children on whom we have distant vision data at all three ages were included. Excluding the other children did not seem to $\overline{0}$ introduce any bias; the percentage of the 8339 who fell into each vision group at any one screening was the same as for the total sample $\mathbb{D}$ on whom we had distant vision data at that age-that is, including those on whom we had data only at that screening or at two screenings.

The distribution of children among the various distant vision groups at each age and the numbers changing groups between tests are shown in tables I-III. (Full three-way tables of the children's vision across all three screenings are available from the authors.) Substantial changes in acuity occurred between screenings. Only $86 \%$ of children with normal vision at 7 years had normal vision at 11 (table I), while about $12 \%$ of those who had normal distant vision at 11 had a defect $\frac{3}{3}$ at 16 (table II). Of children with normal distant vision at $7,18 \%$ showed deterioration of at least one line in one or both eyes by the age of 16 (table III). Indeed, $11 \%$ of children with normal vision at 7 had a definite visual defect by the age of 16 . Conversely, of the 471 children 윽 with a severe bilateral defect at 16, no fewer than $288(61 \%)$ had had $\mathrm{N}$ normal vision at the age of 7 , while only $48(10 \%)$ had a severe $\sigma$ bilateral defect at both ages.

More children's vision apparently improved between 7 and 11 than between 11 and 16 years. Much of the improvement was of only one $N$ or two lines in one eye, and such a change is easily explained by the technical problems of testing at an early age. Because the improvement $\omega$ between the ages of 11 and 16 seemed less explicable in terms of difficulties in testing, the medical records of children with severe

TABLE I-Distant visual acuity of 8339 children at 7 in relation to their distant visual acuity at 11 . Results are numbers and percentages of children

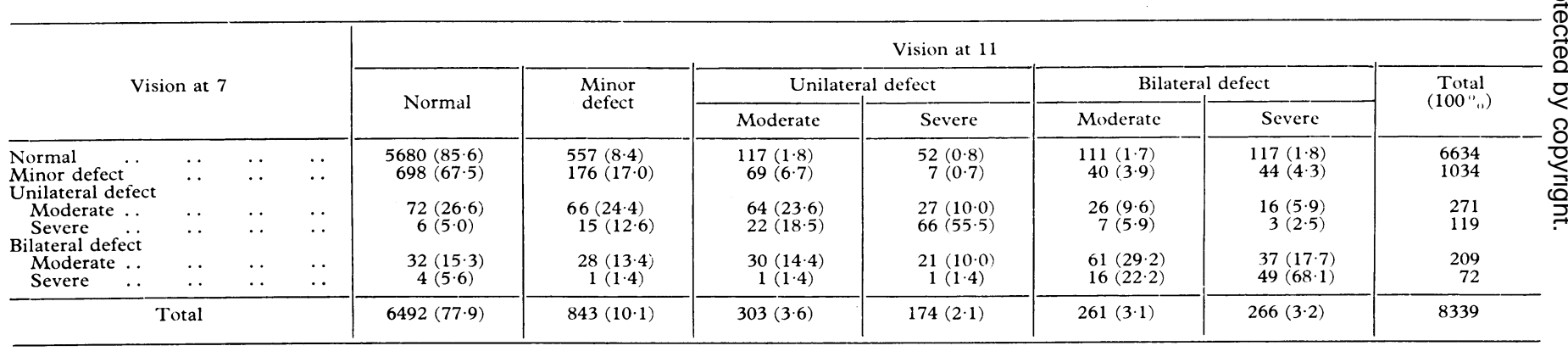


TABLE II-Distant visual acuity of 8339 children at 11 in relation to their distant visual acuity at 16 . Results are numbers (and percentages) of children

\begin{tabular}{|c|c|c|c|c|c|c|c|c|c|c|}
\hline & & & & \multicolumn{7}{|c|}{ Vision at 16} \\
\hline \multirow{2}{*}{\multicolumn{4}{|c|}{ Vision at 11}} & \multirow{2}{*}{ Normal } & \multirow{2}{*}{ Minor } & \multicolumn{2}{|c|}{ Unilateral defect } & \multicolumn{2}{|c|}{ Bilateral defect } & \multirow{2}{*}{$\begin{array}{c}\text { Total } \\
\left(100^{\circ}{ }_{10}\right)\end{array}$} \\
\hline & & & & & & Moderate & Severe & Moderate & Severe & \\
\hline $\begin{array}{l}\text { Normal } \\
\text { Minor defect . } \\
\text { Unilateral defect } \\
\text { Moderate ... } \\
\text { Severe } \\
\text { Bilateral defect } \\
\text { Moderate ... } \\
\text { Severe .. }\end{array}$ & $\begin{array}{l}\cdots \\
\cdots \\
\cdots \\
\cdots \\
\cdots\end{array}$ & $\begin{array}{l}\cdots \\
\cdots \\
\cdots \\
\cdots \\
\cdots\end{array}$ & $\begin{array}{l}\cdots \\
\cdots \\
\cdots \\
\cdots \\
\cdots\end{array}$ & $\begin{aligned} 5678 & (87 \cdot 5) \\
531 & (63 \cdot 0) \\
61 & (20 \cdot 1) \\
2 & (1 \cdot 1) \\
29 & (11 \cdot 1) \\
3 & (1 \cdot 1)\end{aligned}$ & $\begin{array}{c}435(6 \cdot 7) \\
145(17 \cdot 2) \\
74(24 \cdot 4) \\
4(2 \cdot 3) \\
26(10 \cdot 0) \\
2(0 \cdot 8)\end{array}$ & $\begin{array}{c}120(1 \cdot 8) \\
52(6 \cdot 2) \\
78(25 \cdot 7) \\
35(20 \cdot 1) \\
31(11 \cdot 9) \\
3(1 \cdot 1)\end{array}$ & $\begin{array}{l}47(0 \cdot 7) \\
14(1 \cdot 7) \\
31(10 \cdot 2) \\
99(56 \cdot 9) \\
11(4 \cdot 2) \\
1(0 \cdot 4)\end{array}$ & $\begin{aligned} & 132(2 \cdot 0) \\
& 60(7 \cdot 1) \\
& 36(11 \cdot 9) \\
& 22(12 \cdot 6) \\
& 75(28 \cdot 7) \\
& 31(11 \cdot 7)\end{aligned}$ & $\begin{array}{c}80(1 \cdot 2) \\
41(4 \cdot 9) \\
23(7 \cdot 6) \\
12(6 \cdot 9) \\
89(34 \cdot 1) \\
226(85 \cdot 0)\end{array}$ & $\begin{array}{r}6492 \\
843 \\
303 \\
174 \\
261 \\
266\end{array}$ \\
\hline \multicolumn{4}{|c|}{ Total } & $6304(75 \cdot 6)$ & $686(8 \cdot 2)$ & $319(3.8)$ & $203(2 \cdot 4)$ & $356(4 \cdot 3)$ & $471(5 \cdot 6)$ & 8339 \\
\hline
\end{tabular}

TABLE III-Distant visual acuity of 8339 children at 7 in relation to their distant visual acuity at 16. Results are numbers (and percentages) of children

\begin{tabular}{|c|c|c|c|c|c|c|c|c|c|c|}
\hline & & & & \multicolumn{7}{|c|}{ Vision at 16} \\
\hline \multirow{2}{*}{\multicolumn{4}{|c|}{ Vision at 7}} & \multirow{2}{*}{ Normal } & \multirow{2}{*}{$\begin{array}{l}\text { Minor } \\
\text { defect }\end{array}$} & \multicolumn{2}{|c|}{ Unilateral defect } & \multicolumn{2}{|c|}{ Bilateral defect } & \multirow{2}{*}{$\begin{array}{c}\text { Total } \\
\left(100_{0}\right)\end{array}$} \\
\hline & & & & & & Moderate & Severe & Moderate & Severe & \\
\hline $\begin{array}{l}\text { Normal } \\
\text { Minor defect } \\
\text { Unilateral defect } \\
\text { Moderate .. } \\
\text { Severe } \\
\text { Bilateral defect } \\
\text { Moderate ... } \\
\text { Severe .. }\end{array}$ & $\begin{array}{l}\cdots \\
\cdots \\
\cdots \\
\cdots\end{array}$ & $\begin{array}{l}\cdots \\
\cdots \\
\cdots \\
\cdots \\
\cdots\end{array}$ & $\begin{array}{l}\cdots \\
\cdots \\
\cdots \\
\cdots \\
\cdots\end{array}$ & $\begin{array}{r}5413(81 \cdot 6) \\
722(69 \cdot 8) \\
106(39 \cdot 1) \\
13(10 \cdot 9)\end{array}$ & $\begin{array}{c}476(7 \cdot 2) \\
132(12 \cdot 8) \\
49(18 \cdot 1) \\
7(5 \cdot 9)\end{array}$ & $\begin{array}{c}164(2 \cdot 5) \\
47(4 \cdot 5) \\
\\
49(18 \cdot 1) \\
22(18 \cdot 5)\end{array}$ & $\begin{array}{l}85(1 \cdot 3) \\
20(1 \cdot 9) \\
20(7 \cdot 4) \\
60(50 \cdot 4)\end{array}$ & $\begin{array}{r}208(3 \cdot 1) \\
50(4 \cdot 8) \\
22(8 \cdot 1) \\
10(8 \cdot 4)\end{array}$ & $\begin{array}{r}288(4 \cdot 3) \\
63(6 \cdot 1) \\
25(9 \cdot 2) \\
7(5 \cdot 9)\end{array}$ & $\begin{array}{r}6634 \\
1034 \\
271 \\
119\end{array}$ \\
\hline \multicolumn{4}{|c|}{ Total } & $6304(75 \cdot 6)$ & $686(8 \cdot 2)$ & $319(3 \cdot 8)$ & $203(2 \cdot 4)$ & $356(4 \cdot 3)$ & $471(5 \cdot 6)$ & 8339 \\
\hline
\end{tabular}

TABLE IV-Acuity at 16 of children with normal vision at 7 and 11 and of children with normal vision at 7 and minor defects at 11

\begin{tabular}{|c|c|c|c|c|c|c|c|}
\hline \multirow{2}{*}{ Vision at $16:$} & \multirow{2}{*}{ Normal } & \multirow{2}{*}{$\begin{array}{l}\text { Minor } \\
\text { defect }\end{array}$} & \multicolumn{2}{|c|}{ Unilateral defect } & \multicolumn{2}{|c|}{ Bilateral defect } & \multirow{2}{*}{ Total } \\
\hline & & & Moderate & Severe & Moderate & Severe & \\
\hline $\begin{array}{l}\text { Normal vision at } 7 \text { and } 11 \\
\text { Normal vision at } 7, \text { minor defect at } 11\end{array}$ & $\begin{array}{r}4997(88 \cdot 0) \\
382(68 \cdot 6)\end{array}$ & $\begin{array}{l}359(6 \cdot 3) \\
74(13 \cdot 3)\end{array}$ & $\begin{array}{r}102(1 \cdot 8) \\
22(3 \cdot 9)\end{array}$ & $\begin{aligned} 40(0.7) \\
5(0.9)\end{aligned}$ & $\begin{array}{r}111(2 \cdot 0) \\
40(7 \cdot 2)\end{array}$ & $\begin{array}{l}71(1 \cdot 3) \\
34(6 \cdot 1)\end{array}$ & $\begin{aligned} 5680(100) \\
557(100)\end{aligned}$ \\
\hline
\end{tabular}

defects at 11 who had normal vision or a minor defect at 16 were scrutinised. In nearly all these cases doctors confirmed in a supplementary question that the child had a visual defect at 11 . But their comments clearly indicated that there were problems in testing children's vision even at the ages of 11 and 16 .

Acuity seemed to deteriorate most appreciably in the later years. For example, more children deteriorated from the severe unilateral to the bilateral groups or from the moderate bilateral to the severe bilateral group between 11 and 16 than between 7 and 11 .

Table IV shows the visual acuity at 16 of those who had normal vision at the ages of both 7 and 11 . Six per cent of these 16 -year-olds had a definite defect. Among children with normal vision at 7 but a minor defect at 11 (table IV) as many as $18^{\circ}$ o had a definite defect at age 16 , including $13 \%$ with a bilateral defect.

\section{SEX AND SOCIAL CLASS DIFFERENCES}

There was no sex difference in changes in acuity between 7 and 11, but between 11 and 16 , within the group of children from manual social class backgrounds, more girls than boys showed deterioration from normal vision $(P<0.01$; significance levels were adjusted to take account of multiple comparisons by the technique of Gabriel ${ }^{1 i}$ ). Differences did not reach significance within the non-manual group, possibly because of the relatively small numbers.

More children with normal vision at 7 who were of non-manual background had developed a defect by the age of 11 than those of manual background $(\mathrm{P}<0 \cdot 01)$. Much of the deterioration was probably associated with myopia, which is more common among the non-manual group. ${ }^{1 \times 19}$ The social class difference was greatest among children who showed the very sharp deterioration from normal acuity to bilateral severe defect. Among children with normal vision at 11 , more children from non-manual backgrounds than from manual backgrounds showed deterioration in visual acuity by the time they were $16(P<0.05)$.

\section{Discussion}

Our results show that visual acuity cannot be assumed to be constant between the ages of 7 and 16 and that careful, regular screening among schoolchildren is essential.

Ingram' showed that in Kettering and Corby about half of the children discovered with squint or refractive errors associated with squint and amblyopia were over 7 when first discovered. $\mathrm{He}$, and others, ${ }^{20}$ have emphasised the need for effective preschool screening. But even if there is effective preschool screening, regular testing during the school years is also needed. Visual defects may occur at any stage in childhood, and a satisfactory test during the early school years should not lead to complacency about the need for tests later.

Since the visual acuity of as many as one in five children deteriorated between the ages of 7 and 16, the need for regular screening extends to all children, although those with minor defects are in particular need of regular checks. Sheridan warned in 1974 that among children of 5 to 7 years: "a visual acuity of $6 / 9$, even when occurring in only one eye, should be regarded as suboptimal distant vision requiring careful follow-up or, in some cases, immediate referral to a consultant ophthalmologist." Al Altogether $17^{\circ}$ o of the children in the National Child Development Study who had a minor defect at 7 had a definite defect at 16 compared with $11^{\circ} \mathrm{o}$ of those with normal vision at age 7 .

The results of a single screening cannot, however, be used 
for a diagnosis of permanent visual handicap: over three in five children with a minor defect at one screening had normal vision at the next (tables I and II). These improvements were probably more apparent than real, being due partly to the technical difficulties of screening children, especially young primary schoolchildren, in ordinary school settings. As children become older they have better powers of concentration and are less easily distracted; younger children, on the other hand, may underperform because they regard screening as a classroom proficiency test and fear making a mistake. Also, children who are found to have a defect at an early age probably undergo regular, subsequent tests and learn to interpret blurred images, obtaining thereby a rather better test result. Also many children with myopia learn to improve their acuity by as much as two lines by peering between half-closed lids, so that without very careful testing they "overperform" at their later examinations.

Regular screening in the school years is therefore essential to detect the early development of visual defects. Such a system requires adequate back-up services for those identified as needing further assessment. So that children may be protected from having unnecessary treatment or glasses, the specialists to whom the children are referred should have an impartial appreciation of the value of glasses, knowledge of developmental ophthalmology, and a systematic and flexible recall programme. These circumstances are not necessarily found in the current National Health Service arrangements outside the school eye service.

\section{References}

${ }^{1}$ Ingram, R M, British Medical fournal, 1973, 1, 278.

2 Gardiner, P A, British Medical fournal, 1973, 1, 552.

${ }^{3}$ Primrose, J, British Medical fournal, 1973, 2, 177.

${ }^{4}$ Ingram, R M, British Medical fournal, 1973, 2, 548.

${ }^{5}$ Gardiner, P A, British Medical fournal, 1977, 2, 577.

'Cameron, H, British Medical fournal, 1977, 2, 701.

Ingram, R M, British Medical fournal, 1977, 2, 890.

* Peckham, C, and Tibbenham, A, British Medical fournal, 1977, 2, 958.

9 Mulholland, W V, British Medical fournal, 1977, 2, 1083.

${ }^{10}$ Youngson, R M, British Medical fournal, 1977, 2, 1221.

${ }^{11}$ Butler, N R, and Alberman, E D, Perinatal Problems. Edinburgh, Livingstone, 1969

12 Davie, R, Butler, N R, and Goldstein, H, From Birth to Seven. London, Longman, in association with the National Children's Bureau, 1972.

13 Wedge, P J, Concern, 1969, 3, 34.

${ }^{14}$ Fogelman, K, editor, Britain's Sixteen-Year-Olds. London, National@ Children's Bureau, 1976.

${ }^{15}$ Alberman, E D, Butler, N R, and Sheridan, M D, Developmental Medicine $\vec{O}$

and Child Neurology, 1971, 13, 9.
${ }^{16}$ Peckham, C S, and Adams, B, Child Care, Health and Development, 1975, $\overrightarrow{\vec{\omega}}$ 1,93 .

1: Gabriel, F R, Fournal of the American Statistical Association, 1966, 61, 1081 .

1* Douglas, J W B, Ross, J M, and Simpson, H R, fournal of the RoyalStatistical Society, 1967, 130, 479.

${ }^{9}$ Peckham, C S, Gardiner, P A, and Goldstein, H, British Medical fournal, $\vec{N}$ $1977,1,542$.

${ }^{20}$ Brown, M S, Clinical Pediatrics, 1975, 14, 968.

21 Sheridan, M, Developmental Medicine and Child Neurology, 1974, 16, 189. $\frac{\omega}{N}$

\title{
Periurethral aerobic microflora of pregnant and non-pregnant women
}

\author{
INGELA BOLLGREN, VLASTA VACLAVINKOVA, \\ BENGT HURVELL, GUDMUND BERGQVIST
}

British Medical fournal, 1978, 1, 1314-1317

\section{Summary and conclusions}

Seventy-two pregnant and 88 non-pregnant women were examined to see whether the periurethral region had been colonised with group B streptococci (Streptococcus agalactiae), enterococci, and Gram-negative rods belonging to the Enterobacteriaceae. A semi-quantitative method was used for periurethral sampling, and paired urethral swabs were also collected to compare the isolation rates of group $B$ streptococci from the two sites and with the two sampling methods. A higher isolation rate was found with periurethral sampling. Most specimens showed no

\footnotetext{
Department of Bacteriology, National Bacteriological Laboratory, Stockholm, Sweden, and Department of Paediatrics, Karolinska Hospital, Stockholm, Sweden

INGELA BOLLGREN, MD, assistant
}

Department of Gynaecology and Obstetrics, Sabbatsberg Hospital, Stockholm, Sweden

VLASTA VACLAVINKOVA, MD, associate professor

National Veterinary Institute, Stockholm, Sweden BENGT HURVELL, DVM, associate professor

Department of Paediatrics, Central Hospital, Växjö, Sweden GUDMUND BERGQVIST, MD, head of department or scanty growth of Gram-negative rods. Pregnancy was often associated with heavy growth of enterococci. Sampling performed during menstruation and while 0 oral contraceptives were being used produced high isolation rates of group $B$ streptococci.

These results seem to suggest that the periurethral area might protect against genital colonisation with group $B$ 웅 streptococci as it does against urinary tract infection and that hormonal factors influence the carriage of these organisms.

\section{Introduction}

The causal agents of neonatal sepsis and meningitis have changedo over the past 40 years. $\beta$-Haemolytic streptococci of group $A \stackrel{乛}{\Phi}$ were the commonest cause of these infections before 1940, but, $\stackrel{?}{-}$ with the introduction of penicillin, Escherichia coli and other Enterobacteriaceae began to predominate. Since 1960 reports from different countries have incriminated $\beta$-haemolytic $\stackrel{\mathbb{Q}}{\stackrel{9}{\beta}}$ streptococci of group B (Streptococcus agalactiae) along with@ $E$ coli as a major cause of serious neonatal infection. ${ }^{1-4}$ The음 reason for this worldwide emergence of group B streptococci in neonatal disease is unknown. Several studies have shown thato the maternal genital tract is the principal source of infection, at least in the early onset type. "A reasonable hypothesis is that? the microbial flora of the female genital tract has in some way" undergone qualitative or quantitative changes during the last decade, with increased risk of exposing the child to group B streptococci. Attention has been focused on oral contraception 